\title{
2006-1214: PROCESS CONTROL: A RELEVANT APPROACH
}

\section{Barry Barkel, University of Michigan}

Lecturer in Chemical Engineering, University of Michigan

\section{Peter Woolf, University of Michigan}

Assistant Professor of Chemical and Biomedical Engineering, University of Michigan 


\section{Introduction}

Information from many sources, including both new and past graduates, employers and even from a sitting chairman of the AIChE, suggested that the process control course at the University of Michigan was not relevant to the workplace that our graduates were entering. We also conducted interviews with experts actually practicing control engineering in chemical process systems. These sources confirmed the comments we had received. All sources, however, indicated that there are several aspects of process control that graduates do need to know and that these areas were not being covered by current course work.

Based on inputs that the course content provided few useful skills to our students, serious consideration s given to dropping the process control course from the required curriculum. Dropping this course would eliminate the wasted time and energy students spent in a nonproductive pursuit and allow inclusion of new courses in the required curriculum. An alternate proposal involved creating a new course that met the needs of students by including those skills that had been identified as having value in today's workplace. Because the authors felt strongly that graduating engineers must be able to control the processes they designed or managed, we undertook the task of redesigning the process control course.

\section{What}

Several elements of process control were identified as relevant to basic understanding of the material and needed to be included in the new process control course:

- A knowledge of sensors and control devices:

- Reading and creating P \& IDs for process systems

- Developing control "philosophies" and strategies

- Control in biological systems

- Writing control logic for process systems

- Mathematical modeling of process systems

- Dynamic modeling of real systems

- Understanding of convergence, stability and response of systems

- PID controllers and their tuning

- Statistical process control

The design task for the new course was to cover the above material adequately, within a 15-week term, and to do so in a manner that that had flow and continuity. In addition, each section should relate in a logical way.

To accommodate this material, we developed the course plan listed in Table 1. In comparison to the more traditional course plan that we followed previously, this course represents a significant deviation, both in terms of content and emphasis. 


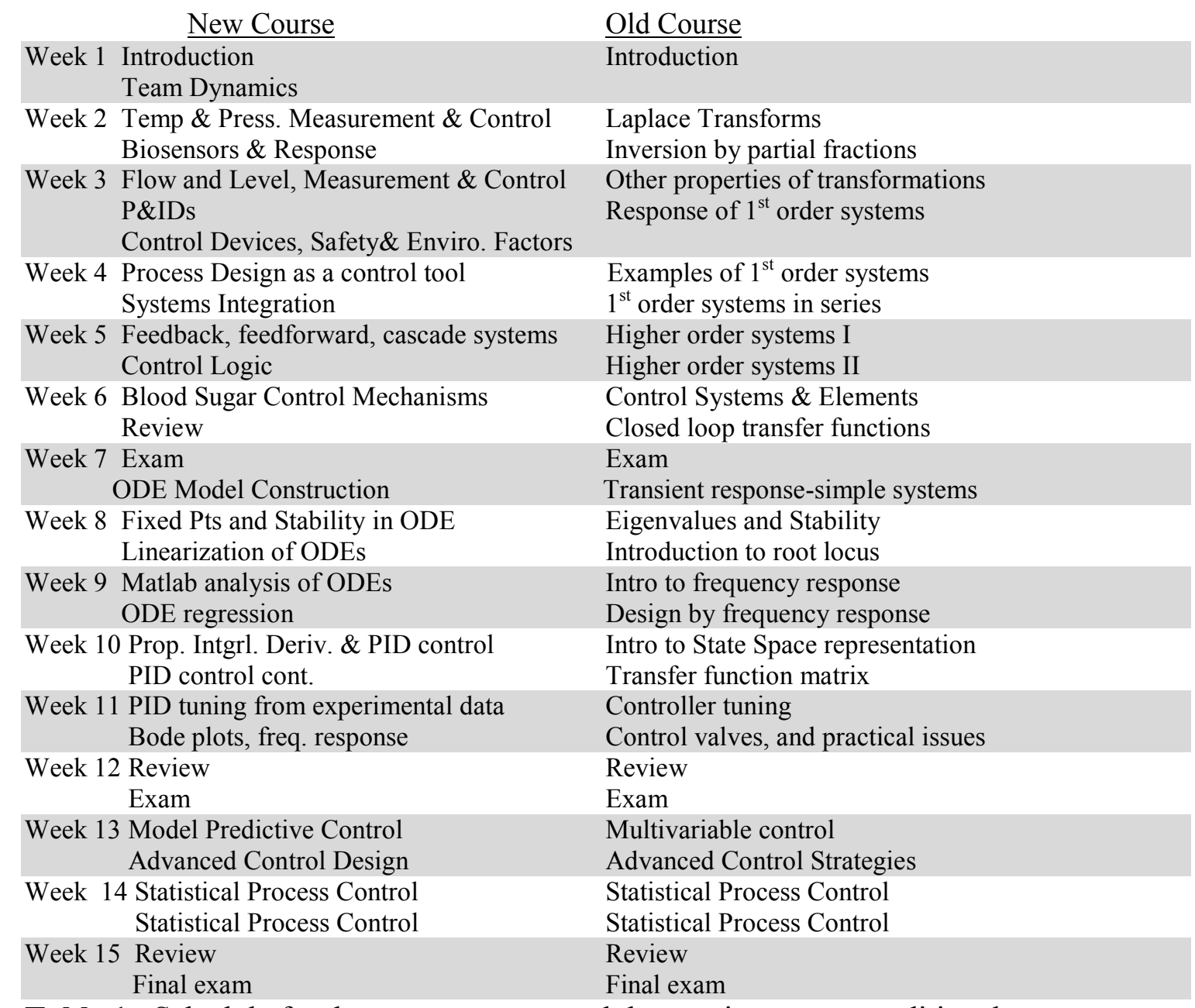

Table 1: Schedule for the current course and the previous, more traditional process control course. Classes meet for two hours per class, twice a week.

\section{Appreciation of the Realities}

While the prior "classical" treatment of controls gave our graduates knowledge of the mathematics that represented how a simple control system would respond, there was little to tie the math to complexity of the real, physical system. We felt it was essential to promote an understanding of how control really works. However, the first three years of the chemical engineering curriculum involves learning the "basics" and focuses strongly on computational solutions to problems with a single answer. Students entering the process control course expected similar single answer computational problems. Indeed, many process control textbooks closely follow this single answer model. However, most real world problems in control have a range of possible solutions. We chose to emphasize the reality of selecting one choice from among a number of alternate 
acceptable answers as an important part of the learning process. While our students have been exposed to open-ended problems in other courses, this exposure was limited.

To help overcome the student discomfort with alternate solutions to the same problem, we used two assignments and an experiment early in the course to focus on the reality and complexity of control. Below we describe these parts of the course in more detail.

The first homework assignment was to instrument an android to mimic human responses. Students were limited to commercially available sensors and control devices to simulate actions such as sleep, exercise, injury, etc. This helped focus them on the detect/respond nature of control.

We emphasize in class that understanding a process and the control objectives are essential to designing a control system. To focus on this understanding, the second homework assignment asked student to develop a list of questions they would ask the master distiller of distillery to enable the process to move from the "art of experience" to effective modern control. This problem served to emphasize the depth of understanding necessary to effect control.

To provide some hands on understanding, an experiment was developed to illustrate the complexity of control (Figure 1). This system uses a variable flow of hot water through a dry ice bed to generate carbon dioxide gas. The control objective is to maintain a constant flow of the product gas. The system was specifically designed as a difficult control system as the $\mathrm{CO}_{2}$ liberation depends on the quantity of dry ice remaining at any given time, the geometry of the dry ice block, and the buildup of ice on the dry ice block. None of these are measurable by the control system-instead the controller has access only to a few temperature and flow measurements shown in the schematic. Students were asked to run the experiment as provided and then develop improvement to the system to make it more controllable. This experience developed a good appreciation of the fact that control parameters are never constant and, like driving a car, keeping things within the boundaries is the only way to manage the task. 


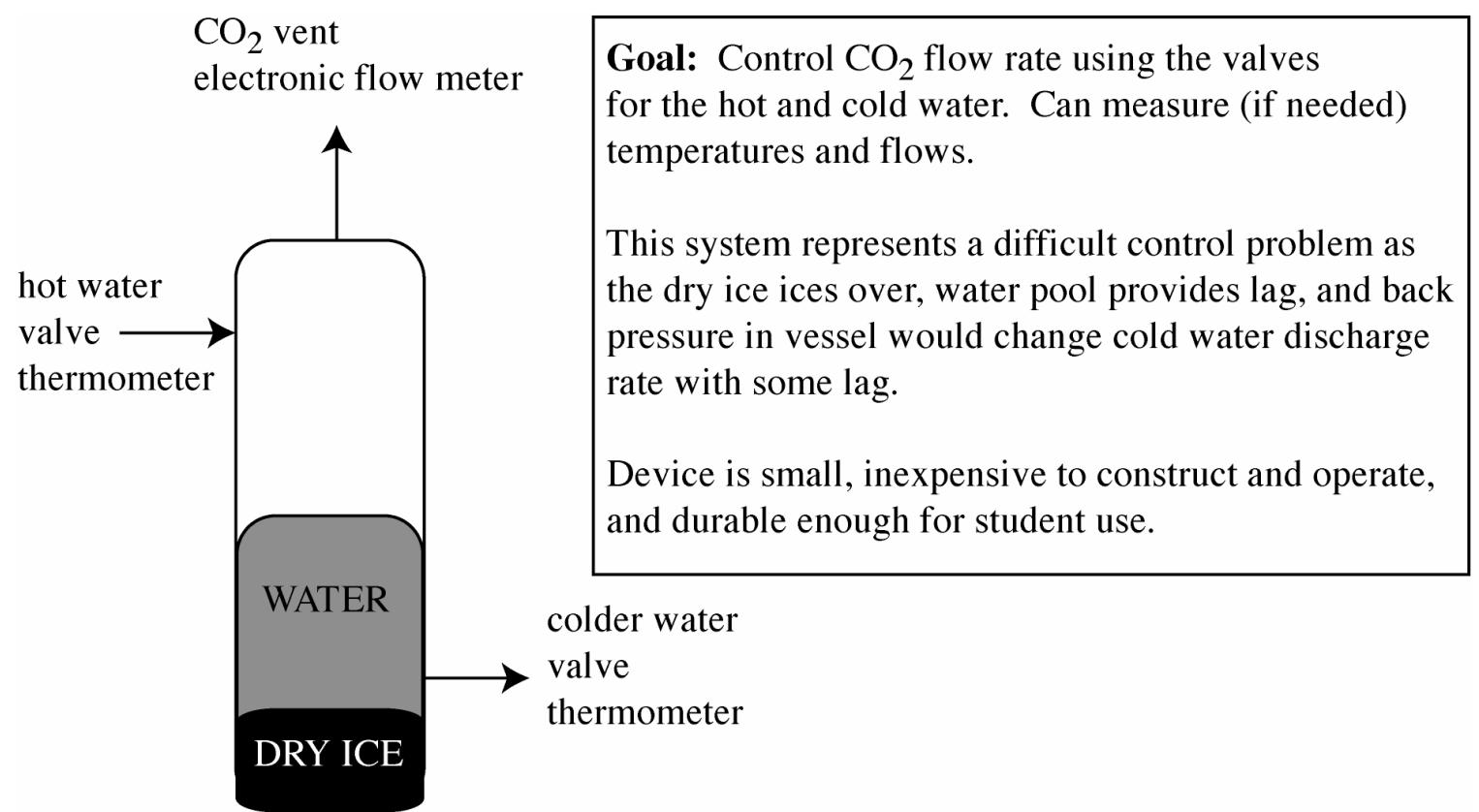

Figure 1: A schematic of a $\mathrm{CO}_{2}$ production experiment used in the course to provide hands on experience for a complex control system.

\section{Sensors, Control Devices, and Systems}

Students have only limited prior knowledge of sensors and control devices and their application. Most of that knowledge comes from contrived situations where the instrumentation has been selected and installed for them in a lab course. These experiences provide little understanding of how to select a device and the device's limitations. Beyond this, these contrived experiences provide little to no understanding of where to place instrumentation to properly control the system. Prior process control courses made no attempt to teach this material despite of its critical role in the field.

In the new course we chose to include more information about the sensors themselves and their rational placement for control. Sensors and control devices do not stand-alone, they must be interrelated to be effective. Most traditional controls texts show this interrelationship as "hard wiring", a direct relationship between a sensor and a control device. Yet modern control systems for the last 20 years or more have routed signals to and from sensors and devices through computers. There the information is processed via mathematical models to select the controller action. The exact routing of data and the processing of responses can become extremely complex and is always a function of the specific system. Yet in most process systems there is a generality of which sensors and control devices are or ought to be interrelated. In the new course, students are taught to recognize these generalities and explore the advantages and disadvantages of specific relationships.

Piping and Instrumentation Diagrams (P\&IDs) are a universally recognized method of communicating sensor and actuator placement in a control system. This basic chemical engineering document was not employed in the prior controls course. To remedy this, 
The University of Michigan Department of Chemical Engineering has developed a technical standard for student P\&IDs that is now used in a number of core courses. This standard is now presented first in the process control course and students are expected to use the instrumentation principles of this standard in their homework and on exams.

From the beginning, we emphasize that controllability is not only a part of the sensors and valves, but also embedded in the architecture of the process itself. The physical configuration of equipment, the sequencing of operations and the conditions under which operations are carried out have as much to do determining the control system as any of the sensor and control devices. The philosophy of the control strategy begins in the physical design. By control philosophy, we mean pre-determining limits on conditions so as to assure safety and optimize the result. A decision to process a material as a highpressure liquid versus low-pressure gas due to easier controllability is an example of establishing a philosophy on the basis of control. Students are taught to recognize that a basic philosophy is important in a control design; it is the focus for the subsequent strategies employed within that control system.

Case studies are used to illustrate the above concepts and the students do homework assignments involving similar process systems to reinforce the principles. A team based project is also assigned where students are given basic chemistry and processing requirements and are required to assemble appropriate equipment and develop the P\&ID of their system showing all instrumentation and the interrelationships among sensor and control devices.

\section{Control in Biological Systems.}

Control in and of biological systems had not previously been included in the Michigan control course. The strong emergence of biological options in chemical engineering has made it imperative to expose students to this area and to demonstrate that, in general, the same control issues apply to living organisms and large chemical complexes alike. In addition, research into biological control mechanisms has suggested a number of such mechanisms that could potentially be applied to non-biological control problems [1].

For the course we introduced two case studies related to biological systems: blood glucose control and bacterial chemotaxis. Throughout the semester we introduced the problem of glucose control via insulin in the human body. Initially, we introduced the physiology of the problem and used a simple pharmacokinetic model of insulin as an alternative example for a logical controller. This model was extended to the Bergman Minimal Model [2,3], to provide a more accurate differential equation model for glucose regulation. Students were assigned a team project to design an insulin injection schedule for a diabetic patient. For this project, students were provided with historical patient data on blood glucose and insulin injections. One of the student programs was tested on the patient - one of the faculty teaching the class.

A second biological case study in the course was the problem of bacterial chemotaxis. In response to a food gradient, a bacterium will perform a biased random walk toward the 
food source. This is a well-studied problem, both biologically [4], and from a controls perspective [5], making it ideally suited for a senior level engineering course. In this case study, students were asked to read the scientific literature and explored the similarities and differences between bacterial chemotaxis and control in a conventional chemical process.

By introducing bacterial chemotaxis, we achieve two ends. First, we expose the students to a relatively unexplored set of questions where the physics, biology, and mathematics are all incomplete. Second, we also introduced the students to the idea of decentralized control, a concept critical to regulating nano-scale machines.

\section{Operating Logic}

Even the most sophisticated hardware system will not function unless it is programmed. The program is what makes the installed control system operational. Previous control courses had not dealt with this issue, yet it is often an area that chemical engineers become involved with early in their careers. Programming can take many forms but it is the general concepts that are important not the specifics. A simple IF... THEN program format was used in the course. The simplicity of this format proved useful as it forced the students to consider actions/reactions in small steps and minimized overlooking factors that might be obscured in a more sophisticated format. Asking the students to write a "story" spelling out what they wanted to the program to accomplish proved to be a very useful tool in developing programming skills. Students usually captured in words, operations that they tended to overlook when working directly a programming format.

Batch systems rather than continuous operations were the primary focus of programming exercises, as is shown in Figure 2 and 3. Continuous systems tend to be less interesting when operating at steady state and the intricacies involved in start-up and shutdown are too complicated to present in an undergraduate controls class. Batch operations have well defined steps in ramping up and ramping down and generally contain a steady state segment in their sequence. From a controls perspective, batch processes are therefore more interesting and illustrative for use in the case studies used in both class and homework.

Because understanding of the effects of program instructions was felt to be as important as knowing how to develop the program, several methods of program analysis were introduced. Truth tables and graphical methods were used to examine the system response to specific inputs, an example of which is shown in Figure 4. Students were also given an assignment where Matlab was used to simulate a process controller. 


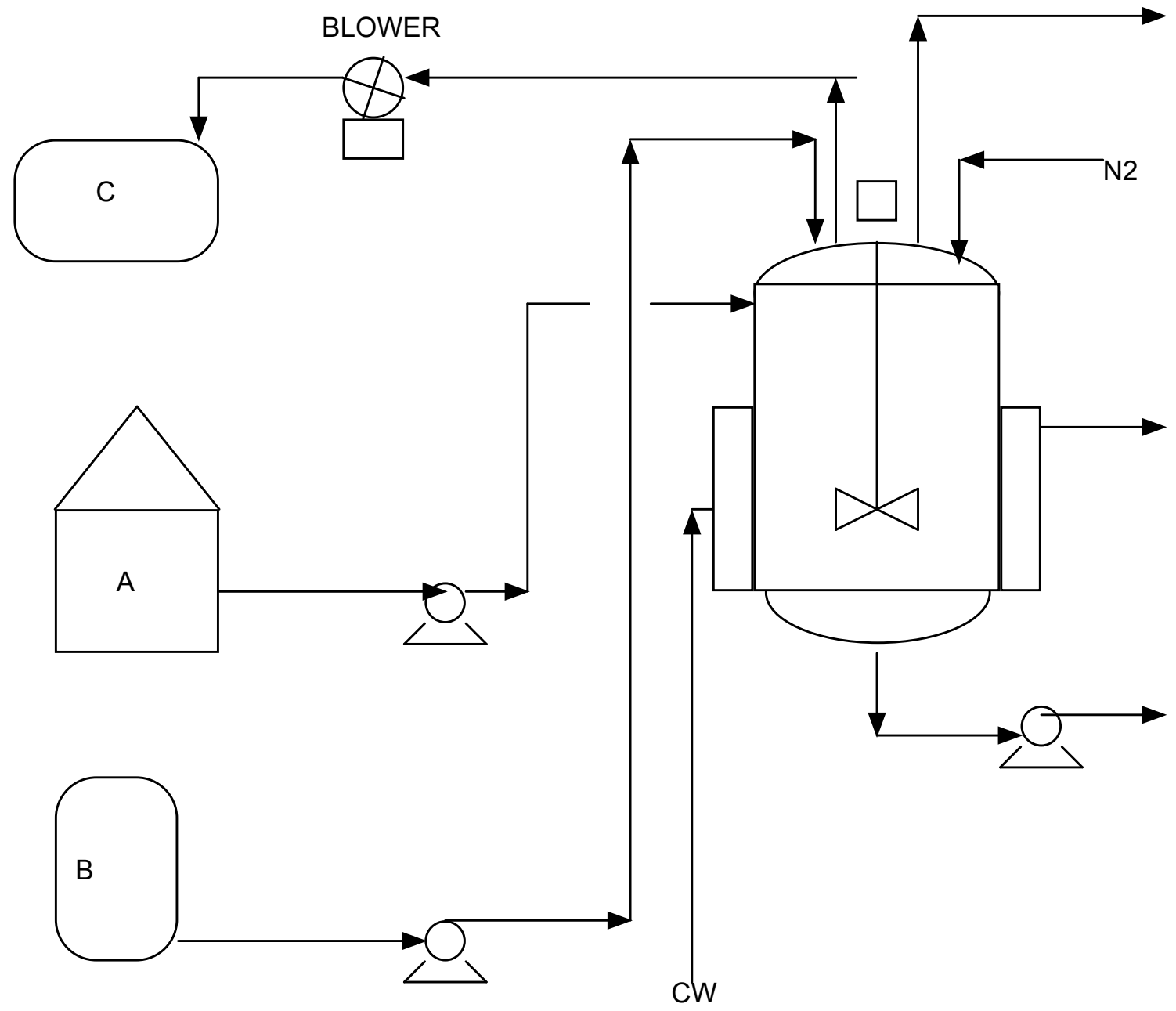

1) Please position the sensors and control devices in this system

2) Please write the control logic for this batch reaction

$$
\begin{aligned}
\mathbf{A}+\mathbf{B}-->\mathbf{C}+\mathbf{A B C}-\mathbf{C B A} & \begin{array}{l}
\text { Reaction is exothermic } \\
\text { It goes to } 100 \% \text { completion }
\end{array}
\end{aligned}
$$

$A$ and $B$ are liquids $\quad B$ is reacted slowly into a full charge of $A$ $C$ is a gas and the product $\mathrm{ABC}-\mathrm{CBA}$ is a waste liquid

\section{Tcw $<$ TRx $<$ TA $<$ TB $<<$ Tabc-cba}

Where: TRx is the reaction temperatueTcw is the water temp andother Ts are the BPs of of the designated species The exotherm is sufficient to get the reaction mass to TRx The reaction is run at $0.5 \mathrm{~atm}$. $\mathrm{C}$ is stored at $1.5 \mathrm{~atm}$

Figure 2: Example control programming problem of a batch process. 


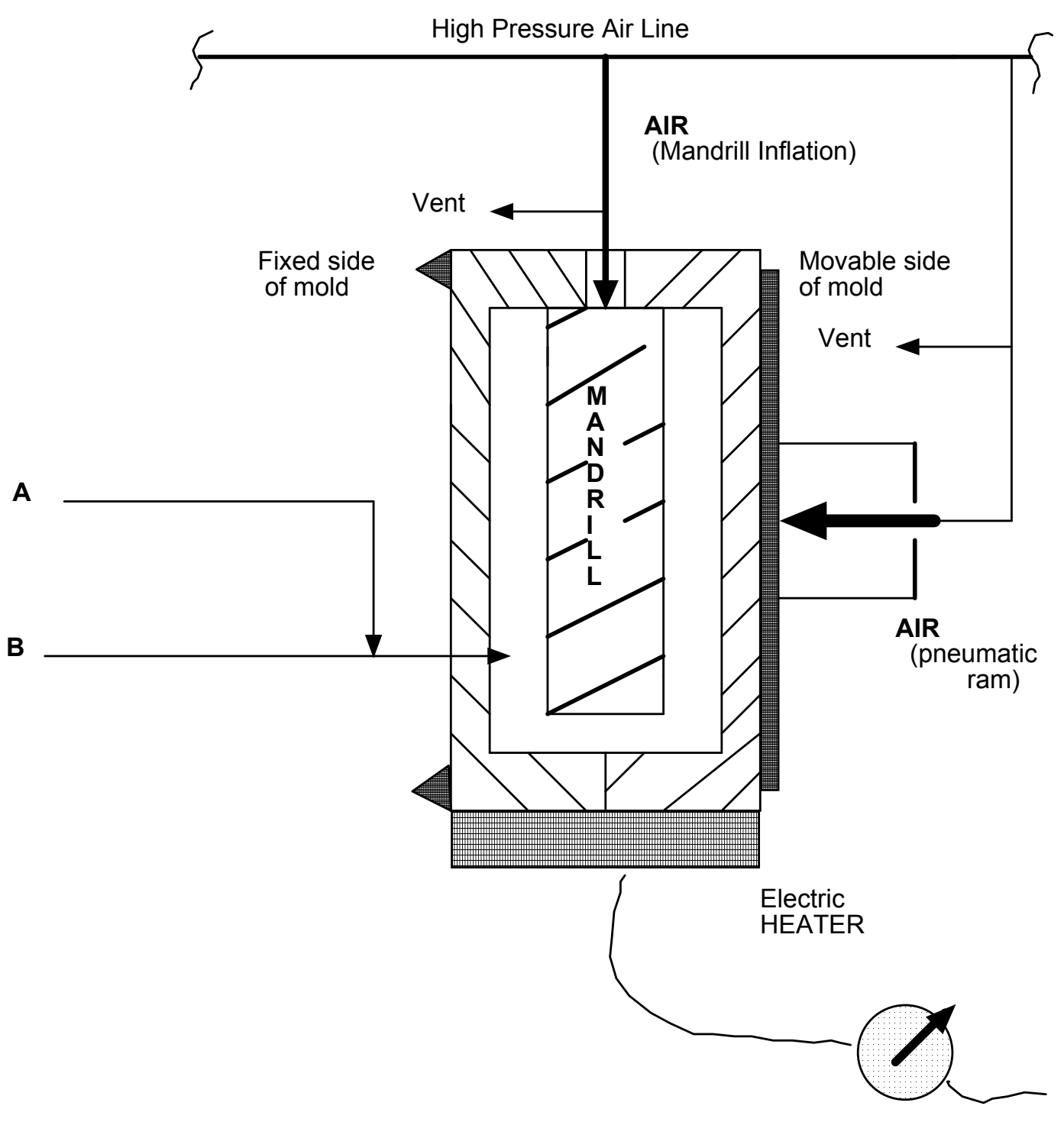

POWERSTAT

A part is manufactured by reactive molding in a 2-piece mold. The 2 halves of the mold are clamped together using pneumatic pressure. Predetermined amounts of $A$ and $B$ are then injected into the $r$ which has been preheated with an electric heater. And expandable mandrill is then "inflated" with ai the desired mold pressure is reached. $A$ and $B$ are then allowed to react for time, at temperature $\mathrm{K}$ and pressure $P R$ The mandrill is then "deflated" and the mold allowed to open so that the part can be removed. The reaction is:2A + B -.> C (to completion)

The reaction is endothermic

1) Please place the sensors and control devices on this equipment, Show relationships.

2) Please write the logic program for this process. Note correct order is essential

Figure 3: An example control programming problem for a molding operation 
Truth table:

\begin{tabular}{|c|c|c|c|c|c|c|c|c|}
\hline entry & $\begin{array}{c}\text { Time ti } \\
\text { IC2 }\end{array}$ & FC2set & FC2 & $\underline{\mathbf{v 1}}$ & $\begin{array}{l}\text { ime tit } \\
\text { IC2 }\end{array}$ & FC2set & FC2 & $\underline{\mathbf{v}_{1}}$ \\
\hline 2 & high & off & on & on & low & off & off & on \\
\hline 4 & high & off & off & on & low & off & off & off \\
\hline 5 & high & on & on & off & high & off & on & on \\
\hline 6 & high & off & on & off & high & off & off & on \\
\hline 7 & high & on & off & off & high & off & on & off \\
\hline 10 & low & off & on & on & low & off & off & on \\
\hline 11 & low & on & off & on & low & off & on & off \\
\hline 12 & low & off & off & on & low & off & off & off \\
\hline 13 & low & on & on & off & high & off & on & on \\
\hline 14 & low & off & on & off & high & off & off & on \\
\hline 15 & low & on & off & off & high & off & on & off \\
\hline
\end{tabular}

State transition graph:

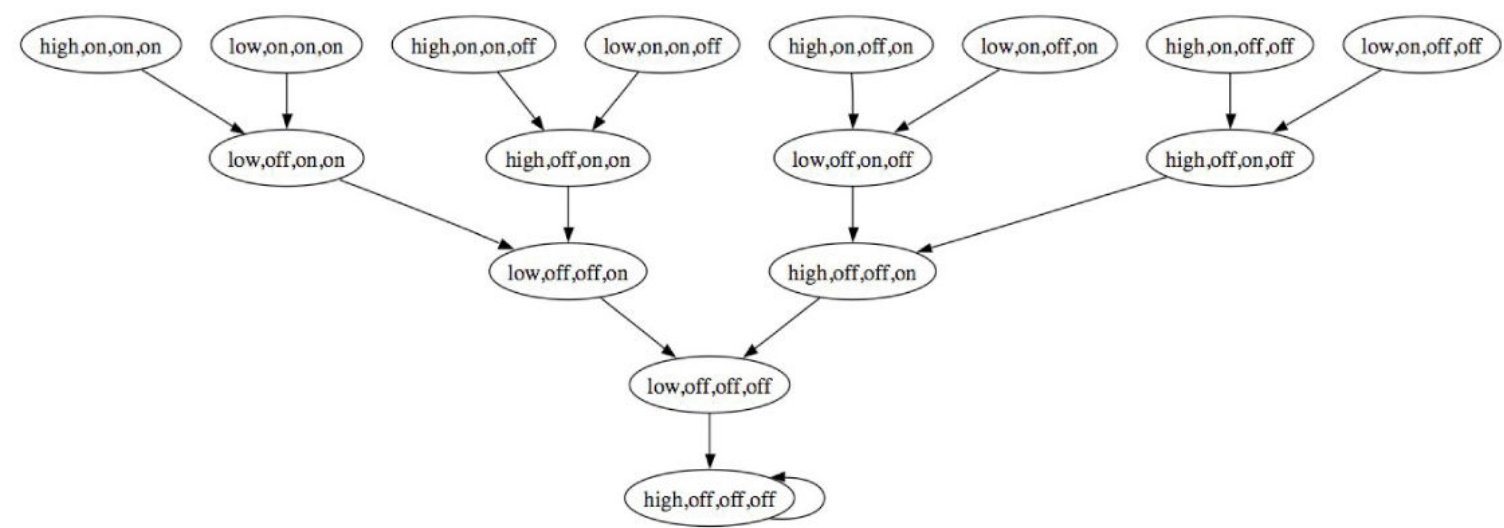

Figure 4: An example of a truth table and state transition graph for a control program developed in the course. Note the parallels between the stability analyses done in continuous systems.

\section{Classical Content}

The concept of system performance is important to understanding control systems and tends to be the central focus of classical control courses. Yet few chemical engineers end up using theses skills in actual practice. Our focus was to provide an appropriate level of understanding of these issues without delving too deeply into the details.

Feed forward, feedback and cascade control were incorporated implicitly from the very beginning by way the P \& IDs and case studies. Later in the course we analyzed these architectures using differential equation based models.

In general, our students were not good at looking at a real process system and writing a simplified yet representative mathematical model of that system. Understanding the natural response in a real system is basic to understanding control of that system. The key to understanding the natural response of a real system is the ability to analyze a real system, determine the most influential variables and mathematically model that system so that the effect of imposed control can be evaluated. Material was presented to emphasize 
the relationship between experimental data and a physical system with models based on ordinary differential equations.

Throughout the course we opted not to teach traditional frequency domain, Laplace transform techniques. While useful in some applications, most frequency domain methods tend to obscure the student's physical and intuitive understanding of the process. In contrast, much of the chemical engineering curriculum is based in the language of ordinary differential equations. As such, students come into the course with some ability to solve, analyze, write, and interpret ordinary differential equations. In the spirit of extending the students ability to solve problems, not perform rote calculations, we cut most of the frequency domain topics from the course.

Convergence, stability and response are concepts necessary to understanding how a control system will behave. To illustrate these concepts, we introduced some concepts from advanced control theory and from nonlinear dynamics, such as phase portraits and incidence graphs [6,7]. For both of these presentations, we emphasized less the theoretical properties of the method, and more the applied uses and intuitive behaviors. As an example, for phase portraits students constructed a possibly nonlinear model of a process, identified stable points, and used Matlab to calculate the trajectory that the system would take to approach the stable point from another point in the space.

Traditional approaches to linearization and stability analysis were also presented and modeled numerically to demonstrate their range of applicability.

Incidence graphs were used as a simplified model of the interactions between process and control variables. Incidence graphs are a way to describe immediate causal relationships between pairs of variables [1]. An example of an incidence graph problem is shown in Figure 5. Both incidence graphs and phase portraits were used in class and as homework assignments.

PID controllers and tuning were covered as particular extensions of the more general nonlinear analysis described above. Here too, incidence graphs and phase portraits proved useful in describing the systems. 
(7) Your company is responsible for producing a novel protein-based therapy for type II diabetes. After significant deliberation, you have come up with the following incidence graph to explain your process to the venture capitalists funding your project.

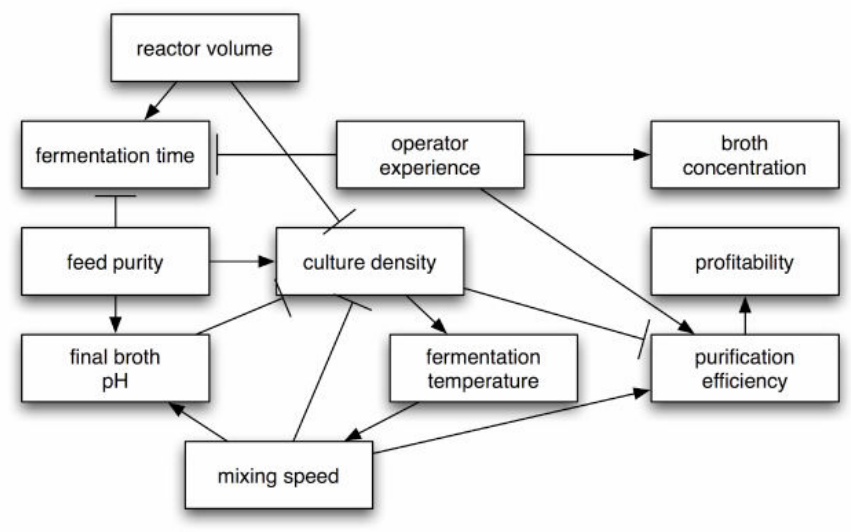

After further discussion, you discover that the venture capitalists really just want to know what variables will increase the profitability of the process. Given the incidence graph alone, what can you say?

Figure 5: This example problem shows how a series of causal activating or repressing relationships can be logically propagated to yield useful insights for control.

\section{Statistical Process Control}

Statistical process control (SPC) is an important form of process control, yet is seldom mentioned in any chemical engineering curriculum. SPC is a control method heavily used in almost every field where chemical engineers work. Industry sources repeatedly mentioned the importance of this type of control and the relative weakness of our graduates in the basic concept of it and the underlying statistical methods.

Somewhat unexpectedly we discovered that to present this topic effectively, a review of statistical principles was required. Remedying this deficiency occupied more time than expected, and will likely occupy a larger part of the course in future versions.

Briefly, SPC is class of methods for improving the reliability of a process and for identifying when a process is out of a user defined control range. The underlying modeling skills for the topic can be simple or involved, depending on the application. From a process control perspective, SPC is valuable in that it tells the user when a control strategy is not working or when the system has changed.

To teach SPC, we chose to emphasize the concepts of six sigma and control charts. Explaining six sigma required the introduction of probability, probability distributions, normal distributions, and z-values. From this foundation, we introduced control charts and how these charts are used to detect a process upsets. 


\section{Difficulties in Course Design}

As with any new course, we found a few surprises and unexpected difficulties along the way.

As mentioned elsewhere, student background for the new material was not uniform. Areas of basic knowledge sometimes had to be reviewed before control material could be presented as planned. This should become less of a problem in the future as we adapt the presentation to the material and minor modifications can be made elsewhere in the curriculum once we can more fully define the background needs for this new course.

Of particular concern was the degree of anxiety among student for non-computational, open-ended problems. Remedies for reducing the anxiety associated with open-ended problems are being investigated, as this was not the only class where the problem was observed. Efforts will be made to increase the increase the open-ended content earlier in the curriculum to remove this distraction from learning at the senior level.

Finding an appropriate textbook is also an outstanding challenge for this course. Some texts such as those by Bequette[3], Stephanopoulos[8], Marlin[9], and Riggs[10] cover portions of the material, but tend to emphasize mathematical techniques more heavily than control strategies for process systems.

Currently the background material for lectures and the course readings are drawn from a large number of sources listed in detail in Table 2. In general, background material is distributed to the class or posted on the class website. Suggested reference readings are also listed for students looking for additional information. However, for many students the lack of a single, comprehensive text is frustrating.

Grading of open-ended solutions such as P\&IDs, control logic programs and team projects is time consuming. Some strides have been made in standardizing solutions through "sectioning" problems into component parts not affected by other parts of the solution. At the same time we recognize that too much standardization will smother the individual creativity, which the course is designed to promote. Complicating the grading issue is that there are relatively few graduate students with a background in many of the areas covered in the new course. Primary instructors must do a large percentage of the grading themselves. It is felt that this new approach to process control will always require a higher than normal work requirement from the instructors. 


\begin{tabular}{|l|l|}
\hline Topic & Source/Reference \\
\hline Team dynamics & Original material \\
\hline $\begin{array}{l}\text { Temperature and pressure, measurement } \\
\text { and control }\end{array}$ & {$[11,12],+$ original material } \\
\hline Biosensors and signaling & {$[2,4,5,13],+$ original material } \\
\hline $\begin{array}{l}\text { Flow and level, measurement and } \\
\text { control }\end{array}$ & {$[11,12],+$ original material } \\
\hline P\&IDs & Original material \\
\hline $\begin{array}{l}\text { Control devices, safety, and } \\
\text { environmental factors }\end{array}$ & Original material \\
\hline Process design as a control tool & Original material \\
\hline Systems integration & Original material \\
\hline $\begin{array}{l}\text { Feedback, feedforward, and cascade } \\
\text { architectures }\end{array}$ & {$[3,10]$} \\
\hline Control logic & {$[1,14],+$ original material } \\
\hline Blood sugar control & {$[2,3]$} \\
\hline ODE modeling of chemical systems & {$[3,12]$} \\
\hline $\begin{array}{l}\text { Fixed points and stability, phase } \\
\text { portraits, and linearization }\end{array}$ & {$[6,7]$} \\
\hline Matlab analysis of ODEs & {$[3]$,} \\
& $\begin{array}{l}\text { PPlane(http://math.rice.edu/ dfield/dfpp.html), } \\
+ \text { original material }\end{array}$ \\
\hline P, PI, and PID control & {$[10,12],+$ original material } \\
\hline PID tuning from data & Original material \\
\hline Bode plots, frequency response & {$[9,12]$} \\
\hline Model predictive control & {$[3],+$ original material } \\
\hline Statistical process control & {$[12,15],+$ original material } \\
\hline
\end{tabular}

Table 2: Sources and references for course handouts and readings.

\section{Course Acceptance \& Results}

Student acceptance of the course was good as determined by standard post course assessments. Scores on questions such as "This was an excellent course" and "I learned a lot in this course" were in the same range as those for other core courses. Many students reported on the open assessment forms that they had learned " a lot". Several students who had served internships in industry reported that they immediately recognized the value of the new material. Many others liked the inclusion of material that directly related to professional practice. There was considerable anxiety early in the course on the "open ended" nature of the material. Some students came to enjoy the creativity that it allowed. Other students, however, were still uncomfortable with the non computational nature of problems even after they had completed the course.

Grades in the class had a normal distribution for a senior level class. Most students had a good mastery of the material by the end of the course, as demonstrated by exam and project results throughout the semester. 
Including more relevant material in the process controls course has had a significant effect on senior process design course, which most students take the following term. Students in process design are required to submit a P\&ID for their project design. In the past these students had only a vague idea of how to control the critical elements in their design. Now students are capable of a fairly sophisticated process analysis and submit P\&IDs very close to the "first pass" control designs found in industry.

\section{Conclusions}

Overall, we feel we have created a new undergraduate process control course that is focused on material relevant to the skill requirement in today's workplace. The efforts described here represent a work in progress. We still have much to learn both in content and in presentation methods. But these first steps have given us a glimpse into how to make what we teach relevant to the needs of industry and our graduates.

\section{References}

1. Sontag, E., Some new directions in control theory inspired by systems biology. Systems Biology, IEE, 2004. 1(1): p. 9-18.

2. Bergman, R.N., L.S. Phillips, and C. Cobelli, Physiologic evaluation of factors controlling glucose tolerance in man: measurement of insulin sensitivity and betacell glucose sensitivity from the response to intravenous glucose. J Clin Invest, 1981. 68(6): p. 1456-67.

3. Bequette, B.W., Process control: modeling, design, and simulation. Prentice-Hall international series in the physical and chemical engineering sciences. 2003, Upper Saddle River, N.J.: Prentice Hall PTR. xxix, 769.

4. Alon, U., et al., Robustness in bacterial chemotaxis. Nature, 1999. 397(6715): p. 168-71.

5. Yi, T.M., et al., Robust perfect adaptation in bacterial chemotaxis through integral feedback control. Proc Natl Acad Sci U S A, 2000. 97(9): p. 4649-53.

6. Khalil, H.K., Nonlinear systems. 3rd ed. 2002, Upper Saddle River, NJ: Prentice Hall. xv, 750.

7. Strogatz, S.H., Nonlinear dynamics and chaos: with applications to physics, biology, chemistry, and engineering. 1st pbk. print. ed. 2000, Cambridge, MA: Westview Press. xi, 498, 4 of col. plates.

8. Stephanopoulos, G., Chemical process control: an introduction to theory and practice. 1984, Englewood Cliffs, N.J.: Prentice-Hall. xxi, 696.

9. Marlin, T.E., Process control: designing processes and control systems for dynamic performance. 2nd ed. 2000, Boston: McGraw-Hill. xxxiii, 1017.

10. Riggs, J., Chemical Process Control. Second Edition ed. 2001, Lubbock, TX: Ferret Publishing.

11. Richardson, J. and D. Peacock, Chemical Engineering Volume 3: Chemical and Biochemical Reactors \& Process Control, ed. J. Richardson and D. Peacock. Vol. 3. 1994: Elsevier. 
12. Lipták, B.G., et al., Instrument engineers' handbook. 3rd ed. 2002, Boca Raton, Fla.: CRC Press. xxxii, 874.

13. Hanahan, D. and R.A. Weinberg, The hallmarks of cancer. Cell, 2000. 100(1): p. 57-70.

14. Raeymaekers, L., Dynamics of Boolean networks controlled by biologically meaningful functions. J Theor Biol, 2002. 218(3): p. 331-41.

15. Breyfogle, F.W., Implementing Six Sigma: smarter solutions using statistical methods. 1999, New York: John Wiley. xxxvii, 791. 